\title{
Institutional barriers to participation in EU framework programs: contrasting the Swiss and UK cases
}

\author{
Marco Cavallaro $^{1}$ (D) $\cdot$ Benedetto Lepori $^{1}$
}

Received: 12 May 2020 / Accepted: 17 November 2020 / Published online: 17 December 2020

(c) The Author(s) 2020

\begin{abstract}
The aim of this study was to examine how institutional barriers arising from policy decisions influence the level of participation of third-party countries in European Framework Programs (EU-FPs). To achieve this, we contrasted the effect of EU funding restrictions following Switzerland's 2014 reclassification as a "third country" in Horizon 2020, and the political uncertainties resulting from the 2016 Brexit vote in the United Kingdom (UK). We compared the participation patterns of Swiss and UK higher education institutions (HEIs) with control groups of similar European HEIs over time and, complementarily, analyzed changes in the participation of small and medium-sized enterprises (SMEs). Our results showed that the Brexit-induced uncertainty had stronger negative effects than the Swiss reclassification, which was, however, characterized by effective EU funding restrictions. In both cases, the negative impact of institutional barriers was stronger for the more central HEIs in EU-FP networks. These results suggest that the effect of institutional barriers is closely linked to consortium building mechanisms, where research collaboration requires stability and projection over the long term. Regarding individual grants, the impact was stronger for Marie Skłodowska-Curie actions than for European Research Council grants, suggesting that a researcher's mobility is affected by political uncertainties. Finally, in the UK case, we observed a steep decrease in the participation of SMEs. Based on these results, we suggest that a stable framework of participation and a clear ruling on relationships with the EU for what concerns people's mobility and economic relationships are key to fostering the participation of third-party countries.
\end{abstract}

Keywords EU Framework Programs · Horizon $2020 \cdot$ FP7 $\cdot$ Research policy $\cdot$ Higher education institutions $\cdot$ Difference-in-difference analysis

Marco Cavallaro

marco.cavallaro@usi.ch

1 Institute of Public Communication, Faculty of Communication, Culture and Society, Università della Svizzera Italiana, Lugano, Switzerland 


\section{Introduction}

Since 1984, European Framework Programs (EU-FPs) have been the main instrument of the European Union (EU) for supporting research and development (R\&D) activities throughout Europe (Georghiou 2001; Ulnicane 2015). EU-FPs benefit from and contribute to the development of the European economic space and research area. The literature analyzing EU-FPs has revealed a convergence at the European level, where country effects are limited and EU-FP participation is highly correlated with organizational characteristics, such as reputation, size, and network centrality, as well as with national investment in R\&D (Enger 2018; Lepori et al. 2015b).

This assumption is likely to be challenged for non-EU countries that participate in EUFPs. On one hand, they are subject to different participation rules. The status of "associated country" grants full access to EU funding as an EU member state in exchange for a financial contribution to the EU-FP budget, while countries without such agreements, referred to as "third-party countries," can participate if they cover their own costs. On the other hand, non-EU countries face potential barriers related to lack of integration into the European R\&D space, EU market access, and intellectual property rights (IPR) rules for companies, as well as researchers' mobility for career schemes.

Moreover, regardless of their associated or third country status, non-EU countries may, at times, face situations of uncertainty in which their eligibility for the next EU-FP is unclear. As EU-FPs require a large entry investment to join central R\&D networks (Enger 2018), uncertainty about future conditions may discourage non-EU participation from both the non-EU participant and EU partners' perspectives.

While the literature mainly analyzes EU-FP participation through network mechanisms, organizational characteristics, and country geography, little is known about the effect of these institutional barriers on non-EU project acquisition. This paper provides evidence on the influence EU funding restrictions and policy-induced uncertainty have on participation in EU-FPs, exemplified by Switzerland's 2014 reclassification to a "third country" and the 2016 Brexit vote in the United Kingdom (UK), which created a lasting uncertainty about UK organizations' future eligibility for EU-FPs (Mayhew 2017).

Within the framework of this study, three types of institutional barriers are examined: (a) EU-FP access restrictions, (b) research mobility limitations, and c) political and economic uncertainty. The focus is primarily on the participation of higher education institutions (HEIs), which benefit from about 40\% of total contributions from Horizon 2020 (H2020), the eighth EU-FP (European Commission 2017). The participation of Swiss and UK HEIs is compared with the participation of control groups of European HEIs before and after the Swiss status reclassification and the Brexit vote. We notably control for the HEIs' centrality in EU-FP networks, which in most of the literature leads to the concentration of EU-FP participation (Paier and Scherngell 2011) and persistence over time (Breschi and Cusmano 2004).

We also investigate the effects on small and medium-sized enterprises (SMEs), which are among the main targets of EU-FPs (Dinges et al. 2013) and may follow a logic of participation different than that followed by HEIs. 


\section{Theoretical framework}

\section{Participation of HEls and non-EU countries in EU-FPs}

The literature on participation in EU-FPs has identified different factors that affect HEIs' level of participation, including organizational size, reputation, and centrality in research collaboration networks (Lepori et al. 2015b; Amoroso et al. 2018; Enger 2018). In general, project participation is highly skewed (Geuna 1996) and generates what some scholars refer to as "oligarchic networks," a pattern that is highly stable and that has even strengthened over years, leading to a small circle of regular participation (Breschi and Cusmano 2004).

Expectedly, the number of acquired EU-FP projects is strongly associated with organizational size as measured by the number of academic staff (Lepori et al. 2015b). Larger HEIs offer higher quality infrastructures and experienced support services, facilitating the acquisition of research grants, and also have greater access to resources and capabilities that reinforce an organization's centrality within European networks (Enger 2018).

Furthermore, organizational reputation is considered a key factor in research grant acquisition at the institutional level (Geuna 2001). This pattern was found also for EUFPs. Based on a sample of 2235 HEIs from 30 countries, Lepori et al. (2015b) conclude that the collaborative nature of EU-FPs reinforces the role of HEIs' reputation in the acquisition of European projects. Reputational factors are also key for EU-FP participation of R\&D-oriented companies (Barajas and Huergo 2010).

Given the collaborative nature of EU-FP projects, relational factors strongly affect participation patterns. Through a social network analysis, Paier and Scherngell (2011) showed that prior collaborative associations and thematic proximity play key roles in the selection of partners and in the stabilization of collaboration networks as explained by the concepts of preferential attachment and network closure (Barber et al. 2006; Autant-Bernard et al. 2007). In their analysis of participation patterns in the 7 th EU-FP, Amoroso et al. (2018) highlighted the importance of geographical, economic, technological, social, and human capital proximity for building R\&D networks. They suggested that EU-FPs have contributed to the development of R\&D networks mainly between close and similar regions and with a high degree of persistence, deepening rather than broadening $R \& D$ networks at the expense of less-developed regions.

Other studies show significant differences within Europe. Geske and Berzina (2017) demonstrated that greater R\&D investments in EU old member states have widened their gap with new member states in terms of EU-FP participation. Regarding the participation of non-EU countries, most studies have not identified a significant correlation between the association status and participation in EU-FPs (e.g., Enger 2018; Lepori et al. 2015b). Mataković and Novak (2013) showed that Croatia, which gained full access to EU-FP in the final year of FP6, had low participation in large research projects and a relatively small number of projects coordinated by Croatian participants in FP7. This points to the difficulty of HEIs that just gained access to EU-FPs to integrate successful R\&D networks.

The relative stability of collaborative networks implies that important initial investments are needed to integrate them, while returns increase with lasting participation. 


\section{Institutional barriers and modes of EU-FP participation}

In this analysis, we distinguish three types of institutional obstacles that can affect participation in EU-FPs. Different effects are expected depending on the project type, the participant's role in the project, and the levels of centrality of the participants in EU-FP networks (Enger 2018).

First, EU-FP access restrictions or limitations range from cases in which HEIs from a non-EU country are not eligible to participate in a funding scheme to cases in which HEIs can participate but are not eligible for funding from the European Commission. For instance, third-party countries are not eligible to participate in European Research Council (ERC) grants or in Marie Skłodowska-Curie actions (MSCAs) but can be partners in collaborative projects with national or institutional sources of funding. For collaborative projects, EU consortia may be less willing to invest in a partner from a nonEU country if its eligibility for EU-FPs is at risk. However, if the non-EU partner is funded by national sources, its attractiveness may increase, as the consortium will benefit from its expertise without requesting more EU funding. This effect is expected to be significant for "peripheral partners" that do not have a central role in the project, while the more central organizations may be penalized by the "third country status," as they would be less strongly integrated into the project.

Similarly, the coordinator's role implies a greater overall responsibility and more direct contact with the European Commission than a partner's role. Accordingly, access restrictions are expected to affect this role to a greater extent, especially for more central organizations.

Researchers' mobility is at the core of the European Research Area (Ackers 2005), and barriers to immigration can affect how researchers perceive a country as a potential research destination (Lepori et al. 2015a). EU-FPs include two funding schemes fostering mobility, i.e., ERC grants and MSCAs. ERC recipients are typically senior researchers with established careers (Robitaille et al. 2015), and their stays at the hosting institution are essentially permanent, as most ERC projects last for up to six years. On the contrary, MSCA grant recipients are typically early-stage researchers, and their stays at the hosting institution are more short-term. For this reason, they are expected to be more directly affected by mobility restrictions.

Finally, political and economic uncertainty can also affect EU-FP participation. Independent of eligibility to participate and to receive EU financing, HEIs may lose their attractiveness as research partners or destinations due to uncertainties affecting future EU-FP access, local immigration policies, and the overall economy. Uncertainties about participation in the EU common market, including also IPR rules, are expected to strongly affect SMEs' participation, as EU consortia investment in SMEs is largely justified by foreseen market uptake. In general, uncertainty is expected to affect central participants in EU-FP networks to a larger extent since their long-term payoffs are larger and more secure than those of peripheral participants.

\section{Swiss vote and Brexit compared}

Our two case studies, i.e., Brexit and the partial exclusion of Swiss participants after the mass immigration vote, imply different types of institutional barriers, also in terms of 
their duration and severity, which are expected to result in different impacts on EU-FP participation.

A popular initiative against mass immigration was adopted by Swiss voters in February 2014, calling on the Swiss Federal Council to take sovereign control over migration in contradiction with the bilateral treaties with the EU (Freitag et al. 2015). Thus, the Swiss Federal Council was no longer in the position to extend the agreement on the free movement of people to Croatia. In response, the European Commission reclassified Switzerland from an associated country to a third country status in H2020 and, therefore, denied Swiss applicants' access to ERC grants, the MSCAs, the SME instrument, and to EU funding for the remainder of the program. In September 2014, the Swiss Federal Council and the European Commission agreed on a transitional solution in which Switzerland was fully associated with the ERC and MSCA schemes but kept its third country status for collaborative projects. Swiss SMEs remained ineligible for the SME Instrument.

Swiss HEIs' concerns regarding the impact of EU funding restrictions were echoed within the Swiss government, which sought to keep established research cooperation by different means, including an ERC backup scheme managed by the Swiss National Science Foundation and by funding Swiss participation in collaborative projects. Ultimately, the Swiss government realigned the implementation of the popular vote and signed the Croatia protocol in December 2016 (Leese 2018). Accordingly, Switzerland regained full access to H2020 at the beginning of 2017. Hence, the Swiss case can be characterized as a short-term shock resulting in temporary EU-FP access limitations, which was quickly absorbed by political diplomacy and did not escalate to questioning the overall relationship between Switzerland and the EU (Armingeon and Lutz 2019).

In June 2016, the UK voted to leave the EU. This implied renegotiating a whole set of relationships with the EU on issues such as access to the European market, customs, and the status of foreigners. Notably, reducing immigration and curbing the free movement of persons was central to the UK political agenda of negotiation (Goodwin and Milazzo 2017). Difficult internal political negotiations led to years of uncertainty regarding the participation of UK institutions in EU-FPs, the enrollment of EU students, and the employment of EU researchers (Mayhew 2017). The Withdrawal Agreement between the EU and the UK, which guaranteed the full eligibility of UK institutions to the last year of H2020, entered into force in February 2020, more than 3 years after the Brexit vote. Moreover, potential restrictions on the movement of persons and the concern that EU students might have to pay the full fee charged to foreign students may affect the attractiveness of UK HEIs and may result in a decrease in enrollment, which may, in turn, heavily impact HEI revenues. This would potentially lead to restructuration in several UK HEIs. In fact, the first figures on researchers' mobility after Brexit show an exodus of EU researchers based in UK HEIs (Corbett and Gordon 2018). The Brexit vote is also leading to a high level of uncertainty among knowledge-based and internationally oriented SMEs, as a negative impact is expected on capital investment and export plans (Brown et al. 2019).

While UK access to H2020 has not been restricted, Brexit-related uncertainties cover more sensible areas for research and innovation, such as immigration and market rules. Accordingly, we expect stronger effects in all project types and roles, particularly for central HEIs in the EU-FP networks. 


\section{Research design}

\section{Data sources and variables}

Three datasets from the EU-funded project RISIS 2 (www.risis2.eu; Grant Agreement 824091) were used to collect organizational and participation data. The EUPRO database provides information on all EU-FP projects and participating organizations from 1984 to 2015. The amount of project participation from 2016 to 2020 (status: September 2020) and the participation data for SMEs are derived from the European Commission's Horizon Dashboard. ${ }^{1}$ For this analysis, projects are attributed to the year of the respective call. The European Tertiary Education Register (ETER; www.eter-project.com) comprises information on European HEIs, such as their basic characteristics and geographical position, educational activities, staff, finances, and research activities. It currently covers 2970 HEIs in 37 countries for the period from 2011 to 2016. Finally, to measure institutional reputation, we used the number of publications belonging to the top $10 \%$ cited in their field; data are derived from the CWTS publication database at the University of Leiden (Waltman et al. 2012).

\section{Methods}

To evaluate the impact of institutional barriers on the participation of HEIs, we used the difference-in-differences (DiD) estimator. The DiD compares changes in outcomes over time between a population that is affected by the occurrence of an event (treatment group) and a population that is not (control group) (Lechner 2010; Meyer 1995). The DiD has the advantage of removing biases within and between the treatment and control groups that could result from permanent differences.

In this paper, the treatment group includes Swiss and UK HEIs, and the control group consists of selected European HEIs with similarities to the treatment group in terms of characteristics affecting EU-FP participation (see "Participation of HEIs and non-EU countries in EU-FPs" section): HEIs' experience in EU-FPs ("FPexp"), size, and reputation. For a reference year (2013 for Switzerland and 2016 for the UK), the treatment observation was matched to controls using the following probit regression:

$$
\operatorname{Prob}(T=1 \mid \text { FPexp, Size, Reputation })
$$

We performed correlation analyses among the control variables listed in Table 1 to design optimized regression models. For right-skewed continuous variables, such as the participation variables "Size" and "FPexp," we used the log transformation to greatly reduce the skewness of their distribution.

The dependent variables were the log transformations of the HEIs' number of times participating in collaborative projects (“CP”), ERC, MSCAs, and the number of projects coordinated (“COORD”).

As treatment variables for the DiD analysis, we created two dummies: "SwissHEI/UKHEI" equals one if the HEI is based in Switzerland or the UK and zero otherwise. "SwissVote/BrexitVote" is a time dummy that takes a value of zero before the Swiss or UK vote, and a value

\footnotetext{
1 European Commission (2020). Horizon Dashboard. Retrieved from: https://ec.europa.eu/info/fundingtenders/opportunities/portal/screen/opportunities/horizon-dashboard.
} 


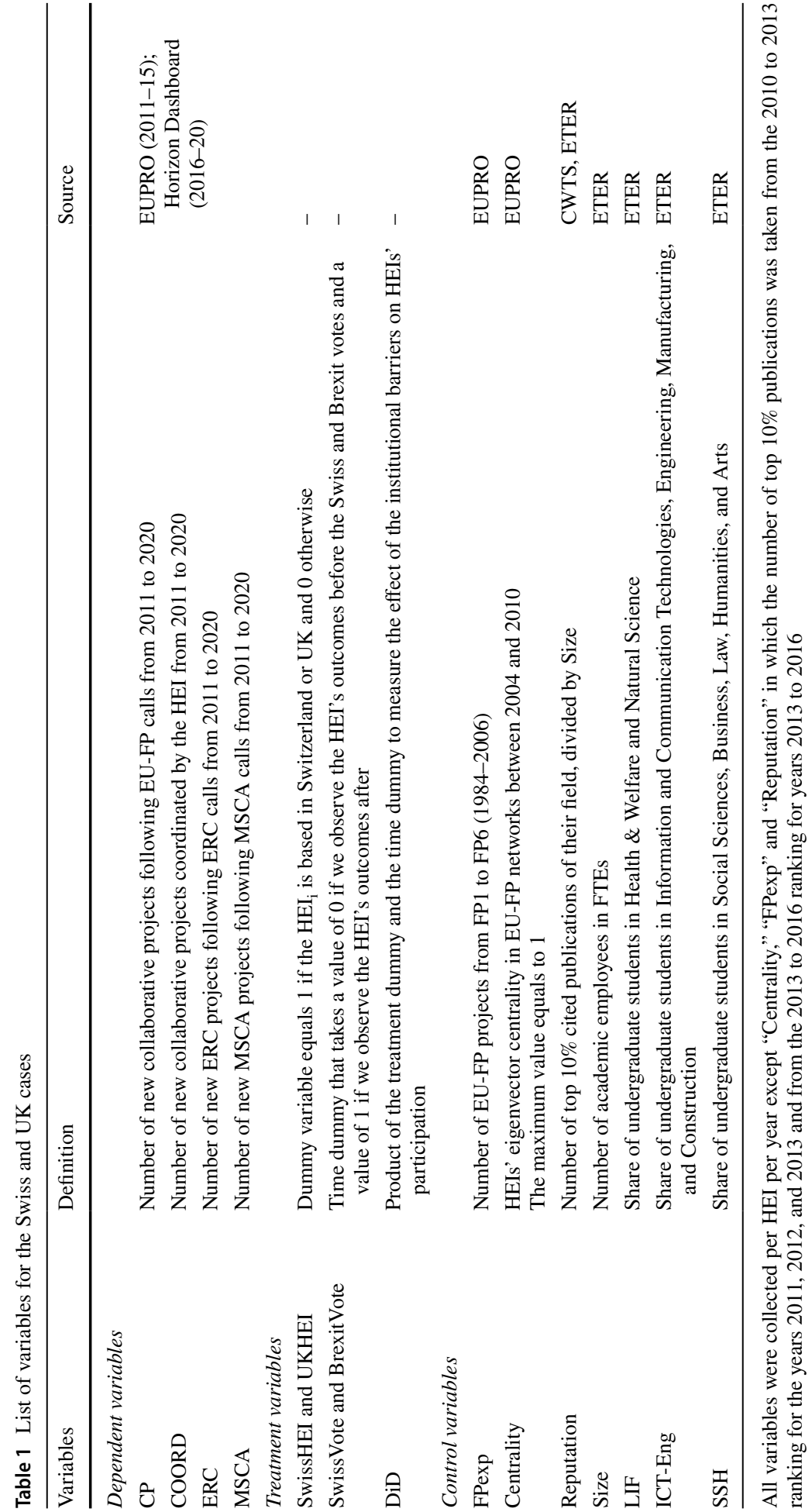


of one if the HEI's outcomes are observed after. The interaction term "DiD," which is the product of "SwissHEI/UKHEI" and "SwissVote/BrexitVote," measures the effect of the Swiss reclassification and the UK vote as the difference in the changes between the treatment and control groups over time.

As control variables, "Centrality" refers to HEIs' eigenvector centrality in the seventh EUFPs ("FP7") from 2007 to 2010. As a measure of centrality, we chose the eigenvector over betweenness, as it distinguishes the prestige of given nodes by considering the centrality of connected nodes (Newman 2008). A high eigenvector score implies that a node is connected to many central nodes. As "Centrality," "FPexp," and "Reputation" are highly correlated, we only selected "Centrality" to account for both network and reputational characteristics of an HEI. "Size" is the log transformation of the number of academic staff. The correlation analysis showed that "Size" is highly associated with "Centrality" and "Reputation," which is in line with the literature on EU-FPs (Enger 2018; Lepori et al. 2015b). Further, we included control variables related to the subject specialization of HEIs, as measured by the composition of the student body, since funding availability varies by field.

In both the Swiss and UK cases, we used two regression models: (1) the "DiD model," in which the "DiD" determined whether institutional barriers had a statistically significant effect on the treatment group's participation, and (2) the "Centrality model," in which we added the interaction term "Centrality*DiD" to measure whether the effect of institutional barriers varied with the HEI's network centrality.

In the Swiss case, 17 Swiss HEIs were matched with two of their closest European counterparts (given the small number of cases). We estimated the following panel regression from 2011 to 2016:

DiD model:

$$
\begin{aligned}
\ln \left(\text { Participations }_{\mathrm{it}}\right)= & \beta_{0}+\beta_{1} \text { SwissHEI }_{\mathrm{i}}+\beta_{2} \text { Swiss Vote }_{\mathrm{it}}+\beta_{3} \text { DiD }_{\mathrm{it}}+\beta_{4} \text { Centrality }_{\mathrm{i}} \\
& +\beta_{5} \ln \left(\text { Size }_{\mathrm{it}}\right)+\beta_{6} \mathrm{LIF}_{\mathrm{it}}+\beta_{7} \text { ICT } \text { Eng }_{\mathrm{it}}+\beta_{8} \text { SSH }_{\mathrm{it}}+\varepsilon_{\mathrm{it}}
\end{aligned}
$$

Centrality model:

$$
\begin{aligned}
& \ln \left(\text { Participations }_{\text {it }}\right)=\beta_{0}+\beta_{1} \text { SwissHEI }_{i}+\beta_{2} \text { Swiss Vote }_{i t}+\beta_{3} \text { DiD }_{\text {it }}+\beta_{4} \text { Centrality }_{\mathrm{i}} \\
& +\beta_{5}(\text { Centrality } * \text { DiD })_{\text {it }}+\beta_{6} \ln \left(\text { Size }_{\text {it }}\right) \\
& +\beta_{7} \mathrm{LIF}_{\text {it }}+\beta_{8} \mathrm{ICT}-\mathrm{Eng}_{\mathrm{it}} \\
& +\beta_{9} \mathrm{SSH}_{\mathrm{it}}+\varepsilon_{\mathrm{it}}
\end{aligned}
$$

In the Brexit case, we compared 98 UK HEIs with a control group composed of 98 nonUK HEIs that were similar in terms of size, reputation, and participation in FP1-FP6. Each HEI was observed 10 times (each year from 2011 to 2020). An analysis incorporating the same control variables as those used in the Swiss case could not be conducted, as most data were not available for the period from 2017 to 2020 . Nevertheless, we used the time-invariant covariate "Centrality" as a measure for network centrality and reputation. We, therefore, estimated the following regressions:

DiD model:

$$
\ln \left(\text { Participations }_{\mathrm{it}}\right)=\beta_{0}+\beta_{1} \text { UKHEI }_{\mathrm{i}}+\beta_{2} \text { BrexitVote }_{\mathrm{it}}+\beta_{3} \text { DiD }_{\mathrm{it}}+\beta_{4} \text { Centrality }_{\mathrm{i}}+\varepsilon_{\mathrm{it}}
$$

Centrality model:

$\ln \left(\right.$ Participations $\left._{\mathrm{it}}\right)=\beta_{0}+\beta_{1}$ UKHEI $_{\mathrm{i}}+\beta_{2}$ BrexitVote $_{\mathrm{it}}+\beta_{3}$ DiD $_{\mathrm{it}}+\beta_{4}$ Centrality $_{\mathrm{i}}+\beta_{5}\left(\text { Centrality }^{2} \text { DiD }\right)_{\mathrm{it}}+\varepsilon_{\mathrm{it}}$ 
In addition to HEIs, we also provide descriptive evidence on the effect of the Swiss reclassification and the Brexit vote on SME participation and coordination of collaborative projects and on the number of SME Instrument grants acquired. We compared the annual numbers of Swiss and UK SMEs with the average participation of five EU countries with high levels of SME participation, namely, Germany, Spain, Italy, France, and the Netherlands.

\section{Results}

\section{Descriptive analysis}

Figure 1 shows patterns of Swiss and UK HEIs' participation and coordination in collaborative projects as compared with their respective control group from 2011 to 2019. The Swiss status reclassification and Brexit vote seem to have affected the participation of Swiss and UK HEIs in collaborative projects. For example, in 2015, Swiss HEIs' average participation decreased, while the control group's was increasing (Fig. 1a). UK HEIs' average participation stagnated in 2017 and 2018 before decreasing in 2019, while the control group acquired on average an increasing annual number of projects after the Brexit vote (Fig. 1b). When compared to other third countries such as the United States and Canada, Swiss HEIs follow similar participation patterns between 2014 and 2016 (Appendix: Fig. 4).
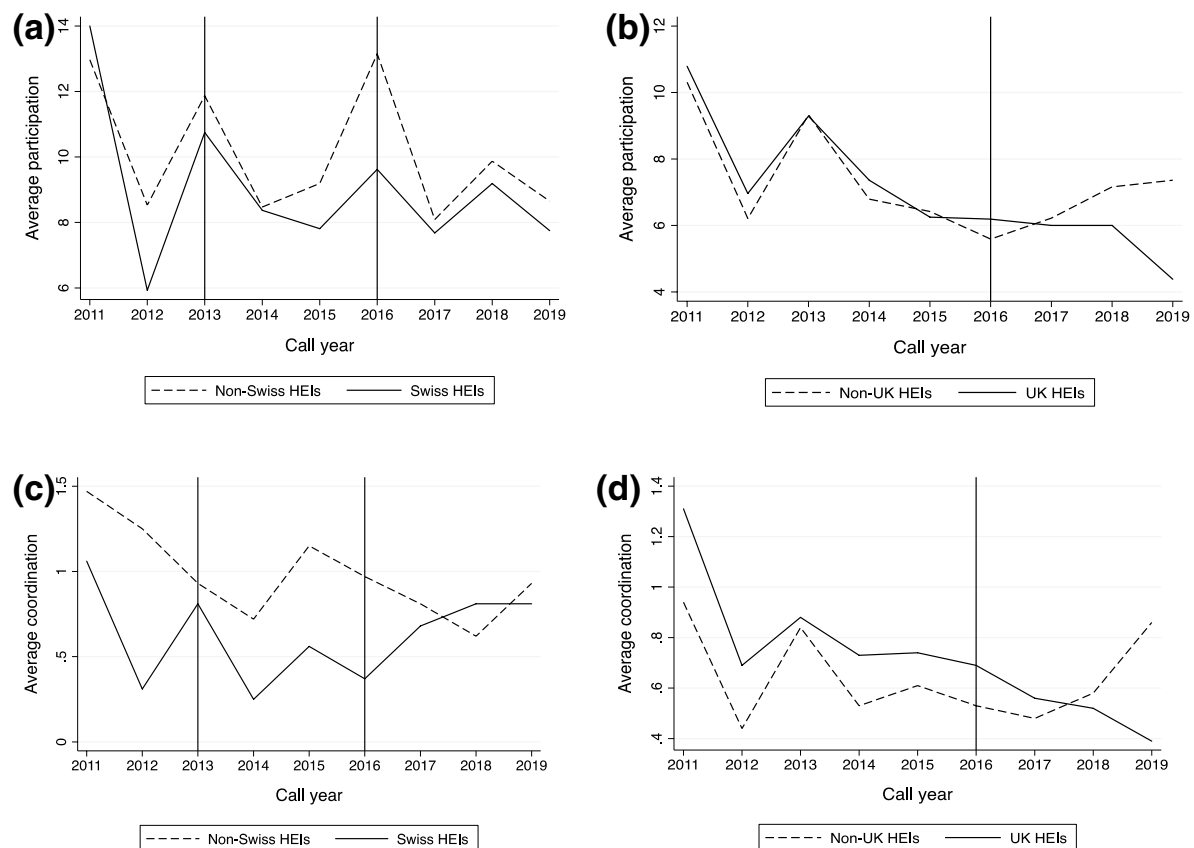

Fig. 1 Average Swiss and non-Swiss HEIs' collaborative project participation (a) and coordination (c) before and after the Swiss reclassification in 2014 and the regaining of the full association in 2017; Average UK and non-UK HEIs' collaborative project participation (b) and coordination (d) before and after the Brexit vote in 2016 
Despite a marked decline in 2014, the number of projects coordinated by Swiss HEIs follows a similar pattern to the control group before observing a full recovery after Switzerland regained full access to EU funding in 2017 (Fig. 1c). The effect of Brexit on UK coordination is particularly salient as, after the vote, the average number of coordinated projects continued decreasing and increasing in the control group (Fig. 1d).

Figure 2 indicates the evolution of the treatment and control groups' participation patterns in ERC and MSCAs. Expectedly, Swiss HEIs' participation in ERC (Fig. 2a) and MSCAs (Fig. 2c) significantly declined from 2013 to 2014 following the loss of eligibility for both schemes from January to September 2014. After regaining full access to both schemes in 2015, Swiss HEIs rapidly attained comparable levels of participation to 2013.

After Brexit, UK HEIs' ERC participation follows similar patterns as the control group (Fig. 2b). The impact of Brexit seems however more significant for MSCAs as the treatment and control groups follow opposite tendencies (Fig. 2d).

Overall, the descriptive analysis shows that Swiss and UK HEIs' average EU-FP participation have been negatively affected by EU funding restrictions and uncertainties, except in the ERC scheme.

To complement patterns in HEI participation, we investigate potential effects on SME participation (Fig. 3). We observe that UK SMEs' participation in collaborative projects and SME Instrument are heavily affected by Brexit-induced uncertainty. Ineligible between 2014 and 2016, Swiss SMEs' participation increased remarkably once they became eligible in 2017 and surpassed UK SMEs in 2018.
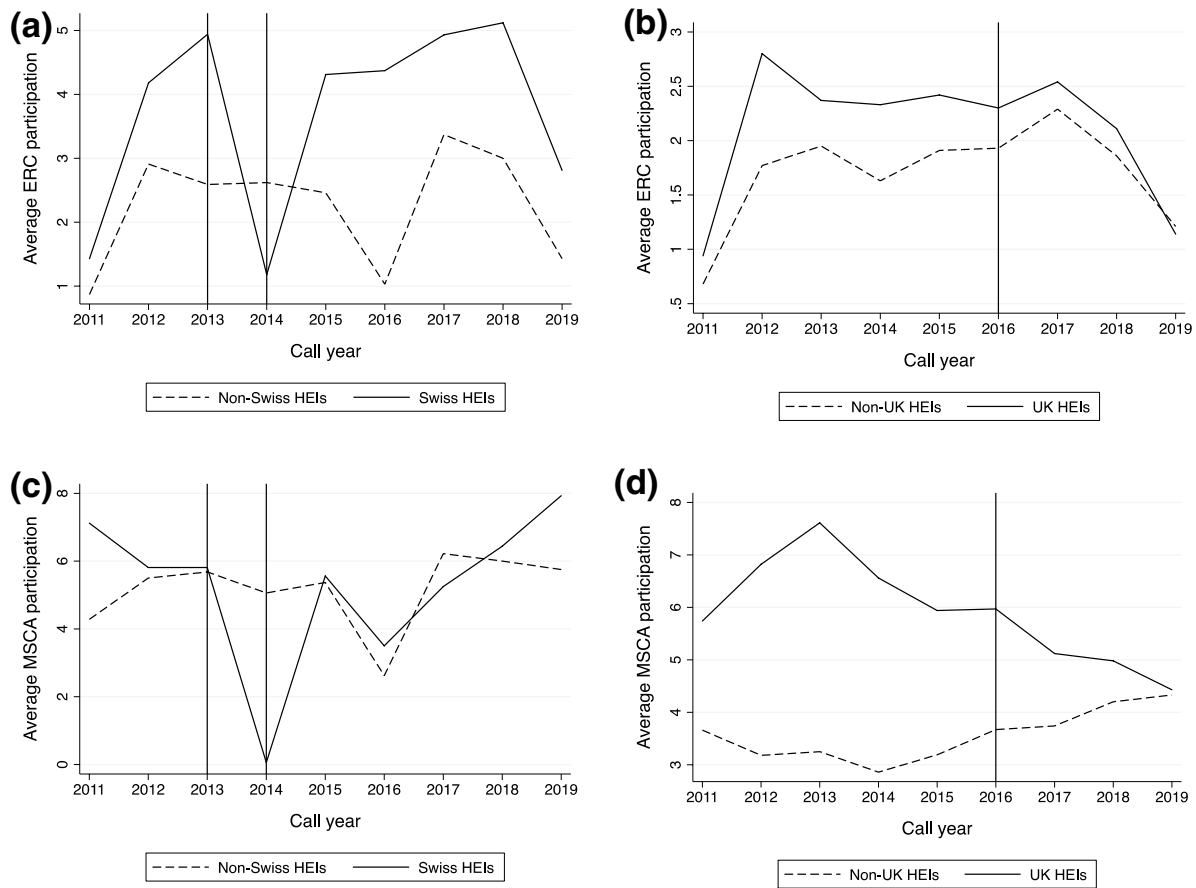

Fig. 2 Average Swiss and non-Swiss HEIs participation in ERC (a) and MSCA (c) before and after the Swiss reclassification in 2014 and the regaining of the full association to these schemes in end 2014; Average UK and non-UK HEIs participation in ERC (b) and MSCA (d) before and after the Brexit vote in 2016 

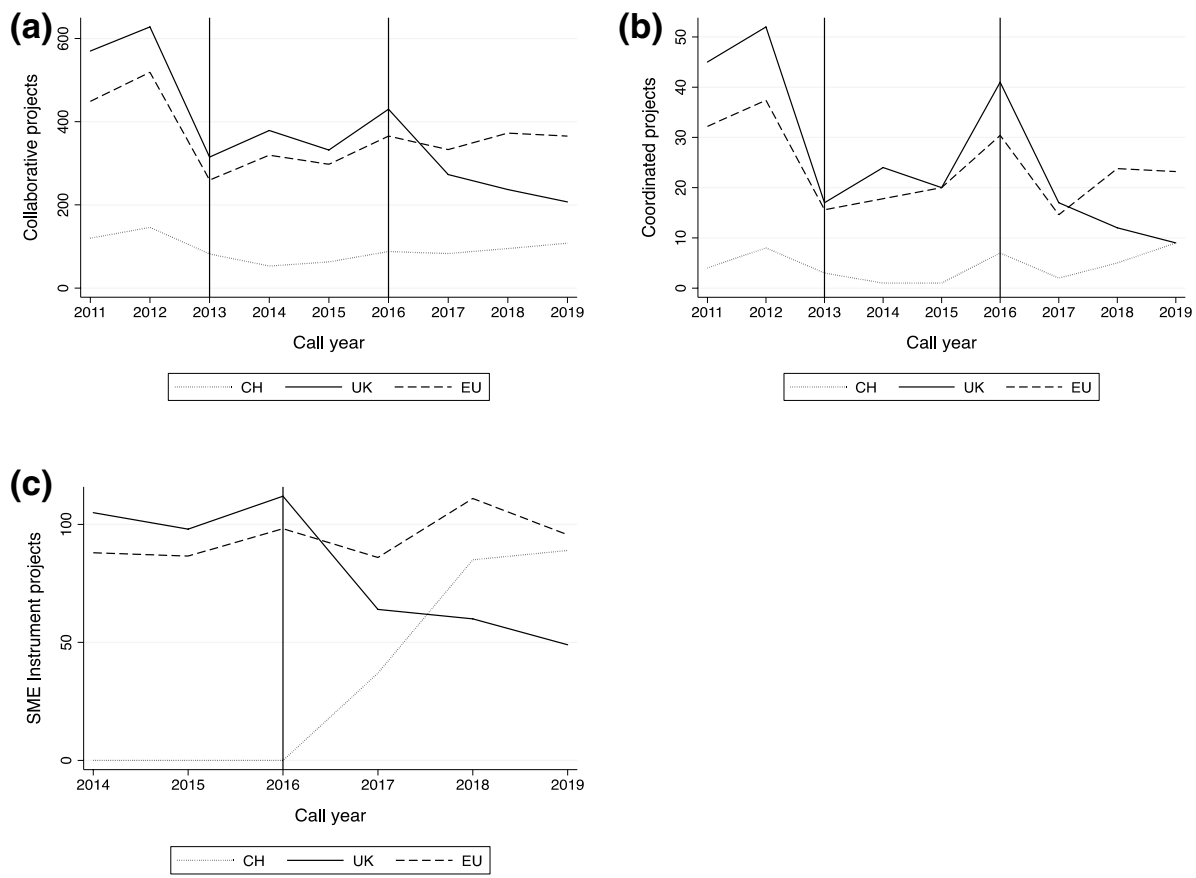

Fig. 3 SME participation in collaborative projects (a), number of coordinated projects (b) and SME Instrument grants (c) before and after the 2014 Swiss reclassification and the 2016 Brexit vote in Switzerland, the UK and average SME participation in Germany, Spain, Italy, France and the Netherlands (EU)

\section{Patterns in project participations and coordination}

Table 2 presents the regression results for the Swiss and UK participation and coordination in collaborative projects. In both cases, patterns revealed by the descriptive analysis are confirmed.

In accordance with our expectations, we do not observe an overall impact of the Swiss vote on Swiss HEIs' participation and project coordination, suggesting that the third country status was broadly equivalent to full participation and did not entail uncertainty on the possibility of participating and the availability of financial means. However, in both cases, the interaction term with centrality is negative and significant, suggesting that more central Swiss HEIs were negatively affected, as they tended to occupy more key roles in the consortia.

The analysis of the UK case provides quite different results, as the "DID model" shows negative correlations between the Brexit vote and UK project participation and coordination in collaborative projects. The results of the "Centrality model" show that these effects are much larger for the more central HEIs $(-0.726 . \mathrm{SE}=0.188, p<0.001$ for participation; $-0.731, \mathrm{SE}=0.192, p<0.001$ for coordination). Considering that the UK status in H2020 did not change, we suggest that these results stem from the uncertainty on future participation rules, both from the perspectives of UK and EU participants, which would not take the risk of keeping UK partners in central roles in consortia. 
Table 2 Linear regression for HEIs' EU-FP collaborative project participation $(\mathrm{CH}, \mathrm{N}=288$; UK, $\mathrm{N}=1451)$ and project coordination $(\mathrm{CH}, \mathrm{N}=103, \mathrm{UK}, \mathrm{N}=605)$

\begin{tabular}{|c|c|c|c|c|c|c|c|c|}
\hline & \multicolumn{4}{|c|}{ Collaborative projects participation } & \multicolumn{4}{|c|}{ Coordination of collaborative projects } \\
\hline & \multicolumn{2}{|l|}{ DiD model } & \multicolumn{2}{|c|}{ Centrality model } & \multicolumn{2}{|l|}{ DiD model } & \multicolumn{2}{|c|}{ Centrality model } \\
\hline & Coef. & $\begin{array}{l}\text { Robust } \\
\text { SE }\end{array}$ & Coef. & $\begin{array}{l}\text { Robust } \\
\text { SE }\end{array}$ & Coef. & Robust SE & Coef. & Robust SE \\
\hline \multicolumn{9}{|l|}{ CH 2011-2016 } \\
\hline SwissHEI & -0.064 & 0.099 & -0.062 & 0.101 & $-0.426^{* *}$ & 0.155 & $-0.421 * *$ & 0.157 \\
\hline Swiss Vote & $-0.384 * * *$ & 0.075 & $-0.383 * * *$ & 0.075 & -0.039 & 0.158 & 0.040 & 0.158 \\
\hline $\mathrm{DiD}$ & 0.085 & 0.139 & 0.354 & 0.184 & -0.274 & 0.223 & 0.355 & 0.304 \\
\hline Centrality & $3.577 * * *$ & 0.205 & $3.721 * * *$ & 0.210 & 0.497 & 0.417 & 0.700 & 0.445 \\
\hline Centrality*DiD & & & $-0.667 * *$ & 0.253 & & & $-0.876^{*}$ & 0.346 \\
\hline Size (ln) & -0.048 & 0.089 & -0.060 & 0.088 & 0.265 & 0.170 & 0.225 & 0.174 \\
\hline LIF & 1.027 & 0.654 & 0.865 & 0.649 & 2.210 & 1.130 & 2.082 & 1.125 \\
\hline ICT-Eng & $1.075^{*}$ & 0.483 & 0.929 & 0.485 & $2.247 *$ & 1.068 & $2.278^{*}$ & 1.052 \\
\hline SSH & 0.301 & 0.531 & 0.101 & 0.538 & 2.052 & 1.059 & 2.048 & 1.046 \\
\hline _cons & 0.031 & 0.885 & 0.231 & 0.882 & -3.564 & 1.606 & $-3.361^{*}$ & 1.614 \\
\hline $\begin{array}{l}\text { R-squared } \\
U K 2011-2020\end{array}$ & 0.8257 & & 0.8293 & & 0.4222 & & 0.4327 & \\
\hline UKHEI & $0.120 * *$ & 0.039 & $0.126 * * *$ & 0.039 & $0.127 *$ & 0.053 & $-0.140 * *$ & 0.053 \\
\hline BrexitVote & $-0.276^{* * *}$ & 0.056 & $-0.279 * * *$ & 0.056 & -0.025 & 0.063 & -0.022 & 0.063 \\
\hline $\mathrm{DiD}$ & $-0.171^{*}$ & 0.080 & 0.144 & 0.103 & $-0.213^{*}$ & 0.092 & 0.186 & 0.124 \\
\hline Centrality & $3.100 * * *$ & 0.059 & $3.225 * * *$ & 0.060 & $1.085^{* * *}$ & 0.081 & $1.226^{* * *}$ & 0.090 \\
\hline Centrality*DiD & & & $-0.726 * * *$ & 0.188 & & & $-0.731 * * *$ & 0.192 \\
\hline _cons & 0.314 & 0.039 & $0.260 * * *$ & 0.039 & $-0.154 * *$ & 0.058 & $-0.243 * * *$ & 0.062 \\
\hline R-squared & 0.6316 & & 0.6364 & & 0.2403 & & 0.2562 & \\
\hline
\end{tabular}

Correlation significant at the $0.001(* * *), 0.01(* *)$, and $0.05(*)$ levels

As expected from the literature, EU-FP network centrality is strongly associated with both collaborative project participation and coordination.

The results for ERC and MSCAs also confirm the tendencies identified in the descriptive analysis.

Table 3 shows that the Swiss reclassification and Brexit vote did not have a statistically significant impact on the participation of Swiss and UK HEIs in ERC grants, and there was no significant impact of centrality on this effect. This might be explained by the fact that ERC participation is mainly driven by the HEI's reputation, which might be affected by access barriers to EU-FPs only in the long term, while future uncertainty on participation is less relevant for these grants. This also shows that there is an important demand from EU and worldwide researchers to obtain access to reputable UK and Swiss HEIs through the ERC, as these are part of the top-ranked European universities.

As expected, the MSCA participations of central Swiss and UK HEIs are negatively affected by their respective institutional barriers $(p<0.01)$. While Swiss HEIs were not eligible for the 2014 calls, UK HEIs kept their formal access to the funding scheme. UK HEIs were nevertheless subject to major immigration-related uncertainties in a program that primarily supports research mobility. We suggest that these uncertainties have harmed the attractiveness of UK HEIs as research destinations.

In both the Swiss and UK cases, centrality and size are strongly and positively associated with the number of MSCA participations $(p<0.001)$. 
Table 3 Linear regressions for participation in ERC grants $(\mathrm{CH}, \mathrm{N}=158$; $\mathrm{UK}, \mathrm{N}=650)$ and MSCAs $(\mathrm{CH}$, $\mathrm{N}=198 ; \mathrm{UK}, \mathrm{N}=1109)$ )

\begin{tabular}{|c|c|c|c|c|c|c|c|c|}
\hline & \multicolumn{4}{|c|}{ ERC participation } & \multicolumn{4}{|c|}{ MSCA participation } \\
\hline & \multicolumn{2}{|l|}{ DiD model } & \multicolumn{2}{|c|}{ Centrality model } & \multicolumn{2}{|l|}{ DiD model } & \multicolumn{2}{|c|}{ Centrality model } \\
\hline & Coef. & $\begin{array}{l}\text { Robust } \\
\text { SE }\end{array}$ & Coef. & $\begin{array}{l}\text { Robust } \\
\text { SE }\end{array}$ & Coef. & Robust SE & Coef. & Robust SE \\
\hline \multicolumn{9}{|l|}{ CH 2011-2016 } \\
\hline SwissHEI & 0.157 & 0.106 & 0.156 & 0.107 & -0.024 & 0.155 & -0.020 & 0.157 \\
\hline Swiss Vote & -0.070 & 0.081 & -0.071 & 0.081 & $-0.226^{* *}$ & 0.158 & $-0.224 * *$ & 0.158 \\
\hline DiD & 0.002 & 0.137 & -0.112 & 0.142 & $-0.381^{*}$ & 0.223 & 0.144 & 0.304 \\
\hline Centrality & $1.448 * * *$ & 0.191 & $1.387 * * *$ & 0.207 & $2.116 * * *$ & 0.417 & $2.396 * * *$ & 0.445 \\
\hline Centrality*DiD & & & 0.283 & 0.261 & & & $-1.301 * *$ & 0.346 \\
\hline Size (ln) & $0.241 * * *$ & 0.067 & $0.247 * * *$ & 0.067 & $0.291 * * *$ & 0.170 & $0.266 * * *$ & 0.174 \\
\hline LIF & 1.157 & 0.632 & 1.226 & 0.641 & $2.300 * * *$ & 1.130 & $1.985 * * *$ & 1.125 \\
\hline ICT-Eng & $1.038^{*}$ & 0.463 & $1.100 *$ & 0.464 & $1.551 * * *$ & 1.068 & $1.268 * *$ & 1.052 \\
\hline SSH & 0.432 & 0.508 & 0.517 & 0.514 & $1.453 * *$ & 1.059 & $1.065^{*}$ & 1.046 \\
\hline _cons & -2.454 & 0.723 & $2.539 * * *$ & 0.726 & $-3.386^{* * *}$ & 1.606 & $-2.996 * * *$ & 1.614 \\
\hline $\begin{array}{l}\text { R-squared } \\
U K 2011-2020\end{array}$ & 0.6061 & & 0.6075 & & 0.7553 & & 0.7738 & \\
\hline UKHEI & $0.181 * *$ & 0.064 & $0.182 * *$ & 0.064 & $0.577 * * *$ & 0.047 & $0.589 * * *$ & 0.046 \\
\hline BrexitVote & 0.092 & 0.075 & 0.092 & 0.075 & 0.052 & 0.056 & 0.051 & 0.057 \\
\hline DiD & -0.168 & 0.118 & 0.154 & 0.190 & $-0.449 * * *$ & 0.085 & -0.138 & 0.116 \\
\hline Centrality & $2.514 * * *$ & 0.104 & $2.604 * * *$ & 0.109 & $3.125^{* * *}$ & 0.068 & $3.253 * * *$ & 0.070 \\
\hline Centrality*DiD & & & -0.533 & 0.318 & & & $-0.655^{* *}$ & 0.207 \\
\hline _cons & $-0.534 * * *$ & 0.066 & $-0.588 * * *$ & 0.067 & $-0.399 * * *$ & 0.047 & $-0.466^{* * *}$ & 0.048 \\
\hline R-squared & 0.4161 & & 0.4187 & & 0.6070 & & 0.4327 & \\
\hline
\end{tabular}

Correlation significant at the $0.001(* *), 0.01(* *)$, and $0.05(*)$ levels

\section{Discussion and conclusions}

The goal of this research was to estimate the impact of institutional barriers on the participation of HEIs in EU-FPs by considering the 2014 Swiss status reclassification and the 2016 Brexit vote in the UK. To this end, we adopted a difference-in-differences approach, comparing the treatment groups of Swiss and UK HEIs with control groups of HEIs presenting similar characteristics.

Although Switzerland had to face effective EU funding restrictions, UK HEIs are encountering more severe uncertainties, as foreseen Brexit-induced complications related to EU 27 researchers' mobility to UK HEIs, lower enrollment of EU students, and subsequent financial difficulties in HEIs resulted in the possibility of EU funding restrictions in future EU-FPs. This is reflected in our results, which suggest that a new agreement, even with less favorable participation conditions, may damage UK HEIs' participation in EU-FPs to a lesser degree than the current situation of uncertainty. The negative effect on the number of projects coordinated by UK HEIs validates Highman's (2018) observation of increasing evidence that UK coordinating roles became jeopardized after Brexit. A more comprehensive study on the effect of Brexit on UK participation that considers similar covariates to the Swiss case can either confirm or disprove these tendencies. 
The impact of institutional barriers has proven to be closely linked to the collaborative nature of EU-FP projects. On one hand, EU consortia are less eager to invest in R\&D partnerships with HEIs from countries that are facing effective and/or foreseen funding restrictions and other uncertainties that are likely to affect R\&D activities during and after the project. On the other hand, potential participants might be less willing to engage in EU-FP networks without a guarantee of long-term returns. In this sense, we suggest that research collaboration in EU-FPs requires stable relationships oriented to the long-term.

Foreseen immigration limitations and other Brexit-induced uncertainties have negatively affected UK HEIs' participation in MSCAs. EU consortia applying for the MSCA innovative training networks may refrain from including UK beneficiaries due to a possible increase in administrative burden when recruiting early-stage researchers. Postdoctoral EU 27 researchers applying for MSCA individual fellowships may be less keen on choosing a UK host organization, given the uncertainty related to their immigration status and career perspectives in the UK.

The results also show how central HEIs are more negatively affected by institutional barriers than peripheral HEIs. Central HEIs, which collect higher numbers of EU-FP projects, have, in fact, more to lose than peripherals in terms of participation when funding restrictions or uncertainty arise. Moreover, due to the Swiss government's funding of Swiss participation between 2014 and 2016, peripheral Swiss HEIs may have become more attractive to EU consortia, which would benefit from their expertise without requesting more EU funding.

In both the Swiss and UK cases, the participation of central HEIs in ERC grants was not impacted by institutional barriers and was strongly correlated with HEIs' integration to EU-FP networks, despite possible research mobility concerns, like in the MSCAs. In 2014, the Swiss ERC backup scheme received a similar number of applications to the number received when Swiss HEIs were eligible for the ERC. In this sense, excluding wellrenowned HEIs from the ERC grants scheme would not be in the interest of the European Commission, as the ERC would lose its attractiveness for its target group.

Our descriptive analysis of SME participation highlights a negative effect of the Brexit vote on UK SMEs' participation in collaborative projects and the SME Instrument. We suggest that Brexit-related uncertainties with regard to capital investment, EU market access, and IPR rules between the UK and the EU are making UK SMEs less attractive to EU consortia as project partners for market uptake and to SME Instrument evaluators as grant recipients. Further research can control for the influence of SME-specific covariates, such as revenues, patent intensity, size, and previous EU-FP participation.

Although our results show how central HEIs can be sensitive to institutional barriers, the results of our research also confirm the strong and positive correlation between network centrality and the accumulation of EU-FP projects, which makes EU-FP participation skewed towards a closed circle of participants. This is in line with most literature on EU-FPs (Enger 2018; Paier and Scherngell 2011). Partners' investments to acquire collaborative projects tend to be lower when they are well integrated to relevant R\&D networks. We, therefore, expect that non-EU HEIs with better reputations will be the main beneficiaries of positive country status changes that guarantee increased or full access to EU-FPs.

Following the same logic, if a non-EU country with a rather low rate of EU-FP participation gains full access to EU-FPs, participation in EU-FPs will grow only slowly in the short-term, as HEIs' integration into the EU R\&D networks and reputation building take time. This has been shown in Mataković and Novak's analysis (2013) of Croatia participation in FP7. In that sense, the partners' investments to enter R\&D networks are higher than the investments needed to maintain collaborative relationships.

Further investigations dealing with positive status changes (e.g., Israel in 1996, Switzerland in 2004, or Ukraine in 2015) or bilateral agreements with third-party countries (e.g., 
the 1998 Agreement for Scientific and Technological Cooperation between the United States of America and the European Community) can qualify these assumptions. Future case studies can also challenge our results by considering longer periods as the cumulative advantages of non-EU HEIs and their reputation may fade over time due to a possible decrease in projects acquired and coordinated.

Funding Open access funding provided by Università della Svizzera italiana.

Open Access This article is licensed under a Creative Commons Attribution 4.0 International License, which permits use, sharing, adaptation, distribution and reproduction in any medium or format, as long as you give appropriate credit to the original author(s) and the source, provide a link to the Creative Commons licence, and indicate if changes were made. The images or other third party material in this article are included in the article's Creative Commons licence, unless indicated otherwise in a credit line to the material. If material is not included in the article's Creative Commons licence and your intended use is not permitted by statutory regulation or exceeds the permitted use, you will need to obtain permission directly from the copyright holder. To view a copy of this licence, visit http://creativecommons.org/licenses/by/4.0/.

\section{Appendix}

See Tables 4, 5, 6, 7 and Fig. 4.

Table 4 Descriptive statistics of variables (Swiss case)

\begin{tabular}{|c|c|c|c|c|c|c|c|c|c|}
\hline & $\mathrm{N}$ & Mean & STDEV & Skewness & MIN & $1 \mathrm{Q}$ & Median & $3 Q$ & MAX \\
\hline $\mathrm{CP}$ & 288 & 9.19 & 13.20 & 2.06 & 0 & 1 & 3 & 11 & 60 \\
\hline COORD & 288 & 0.91 & 1.73 & 2.52 & 0 & 0 & 0 & 1 & 9 \\
\hline ERC & 288 & 2.52 & 4.83 & 2.95 & 0 & 0 & 0 & 3 & 31 \\
\hline MSCA & 288 & 4.72 & 7.94 & 2.55 & 0 & 0 & 1 & 6 & 45 \\
\hline FPexp & 288 & 160.33 & 224.33 & 2.15 & 2 & 11 & 65 & 229.5 & 1069 \\
\hline Reputation & 288 & 0.10 & 0.12 & 0.64 & 0 & 0 & 0 & 0.22 & 0.47 \\
\hline Centrality & 288 & 0.38 & 0.32 & 0.38 & 0 & 0.04 & 0.30 & 0.65 & 1 \\
\hline Size & 288 & 2058.84 & 1629.31 & 1.19 & 407.49 & 732.98 & 1440.15 & 2933.97 & 7094.35 \\
\hline LIF & 288 & 0.20 & 0.09 & -0.13 & 0 & 0.14 & 0.20 & 0.25 & 0.43 \\
\hline ICT-ENG & 288 & 0.21 & 0.21 & 0.94 & 0 & 0.05 & 0.12 & 0.36 & 0.70 \\
\hline $\mathrm{SSH}$ & 288 & 0.50 & 0.21 & -0.17 & 0 & 0.37 & 0.52 & 0.64 & 1 \\
\hline & & & & & \multicolumn{5}{|l|}{$\mathrm{N}$} \\
\hline & & & & & \multicolumn{4}{|l|}{0} & 1 \\
\hline SwissHEI & & & & & \multicolumn{4}{|l|}{192} & 96 \\
\hline SwissVote & & & & & \multicolumn{4}{|l|}{144} & 144 \\
\hline Top100 & & & & & \multicolumn{4}{|l|}{234} & 54 \\
\hline
\end{tabular}


Table 5 Descriptive statistics of variables (UK case)

\begin{tabular}{|c|c|c|c|c|c|c|c|c|c|}
\hline & $\mathrm{N}$ & Mean & STDEV & Skewness & MIN & $1 Q$ & Median & $3 Q$ & MAX \\
\hline $\mathrm{CP}$ & 1960 & 6.54 & 10.02 & 2.73 & 0 & 0 & 3 & 8 & 78 \\
\hline COORD & 1960 & 0.62 & 1.27 & 3.01 & 0 & 0 & 0 & 1 & 10 \\
\hline ERC & 1960 & 1.72 & 4.03 & 4.31 & 0 & 0 & 0 & 1 & 40 \\
\hline MSCA & 1960 & 4.38 & 7.87 & 3.33 & 0 & 0 & 1 & 5 & 66 \\
\hline FPexp & 1960 & 168.37 & 225.06 & 2.24 & 1 & 15.5 & 73.5 & 256 & 1304 \\
\hline \multirow[t]{3}{*}{ Centrality } & 1960 & 0.34 & 0.29 & 0.48 & 0 & 0.07 & 0.28 & 0.56 & 1 \\
\hline & & & & & \multicolumn{5}{|c|}{$\mathrm{N}$} \\
\hline & & & & \multicolumn{2}{|l|}{0} & & & & 1 \\
\hline UKHEI & & & & \multicolumn{2}{|c|}{980} & & & & 980 \\
\hline BrexitVote & & & & \multicolumn{2}{|c|}{1176} & & & & 784 \\
\hline Top100 & & & & \multicolumn{2}{|c|}{1786} & & & & 174 \\
\hline
\end{tabular}

Table 6 Correlation matrix (Swiss case)

\begin{tabular}{|c|c|c|c|c|c|c|c|c|}
\hline & FPexp (ln) & centrality & reputation & top 100 & size $(\ln )$ & LIF & ICT-Eng & $\mathrm{SSH}$ \\
\hline FPexp (ln) & 1 & & & & & & & \\
\hline centrality & $0.8867 *$ & 1 & & & & & & \\
\hline reputation & $0.8023^{*}$ & $0.8658^{*}$ & 1 & & & & & \\
\hline top100 & $0.5553^{*}$ & $0.6301 *$ & $0.6193^{*}$ & 1 & & & & \\
\hline size $(\ln )$ & $0.7199 *$ & $0.8428 *$ & $0.8239 *$ & $0.6185^{*}$ & 1 & & & \\
\hline LIF & $0.3596^{*}$ & $0.4291 *$ & $0.5214^{*}$ & $0.3045^{*}$ & $0.5311^{*}$ & 1 & & \\
\hline ICT-Eng & $-0.2986^{*}$ & -0.1080 & -0.1246 & 0.0182 & -0.0663 & -0.1206 & 1 & \\
\hline SSH & $0.2111^{*}$ & -0.0064 & -0.0348 & -0.1006 & -0.1671 & $-0.3164^{*}$ & $-0.8446^{*}$ & 1 \\
\hline
\end{tabular}

$*=0.001$

Table 7 Correlation matrix (UK case)

\begin{tabular}{llll}
\hline & fpexp $(\ln )$ & centrality & top100 \\
\hline fpexp (ln) & 1 & & \\
centrality & $0.8868^{*}$ & 1 & \\
top100 & $0.3948^{*}$ & $0.4876^{*}$ & 1 \\
\hline
\end{tabular}

$*=0.001$ 


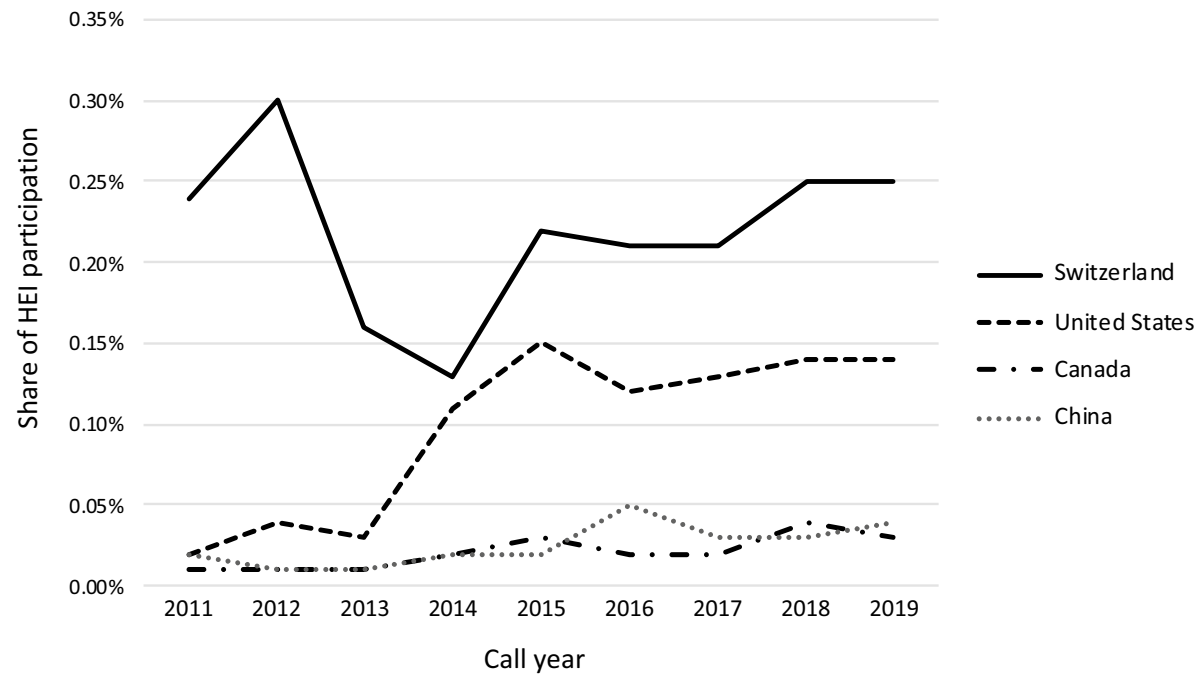

Fig. 4 Share of HEI participation in EU-FPs in Switzerland and third countries with most EU-FP participations

\section{References}

Ackers, H. L. (2005). Promoting scientific mobility and balanced growth in the European research area. Innovation, 18(3), 301-317.

Amoroso, S., Coad, A., \& Grassano, N. (2018). European R\&D networks: a snapshot from the 7th EU Framework Programme. Economics of Innovation and New Technology, 27(5-6), 404-419.

Armingeon, K., \& Lutz, P. (2019). Muddling between responsiveness and responsibility: The Swiss case of a non-implementation of a constitutional rule. Comparative European Politics, 2019, 1-25.

Autant-Bernard, C., Billand, P., Frachisse, D., \& Massard, N. (2007). Social distance versus spatial distance in R\&D cooperation: Empirical evidence from European collaboration choices in micro and nanotechnologies. Papers in Regional Science, 86(3), 495-519.

Barajas, A., \& Huergo, E. (2010). International R\&D cooperation within the EU framework program: Empirical evidence for Spanish firms. Economics of Innovation and New Technology, 19(1), 87-111.

Barber, M. J., Krueger, A., Krueger, T., \& Roediger-Schluga, T. (2006). Network of European Unionfunded collaborative research and development projects. Physical Review E, 73(3), 036132.

Breschi, S., \& Cusmano, L. (2004). Unveiling the texture of a European research area: Emergence of oligarchic networks under EU framework programs. International Journal of Technology Management, 27(8), 747-772.

Brown, R., Linares-Zegarra, J., \& Wilson, J. O. S. (2019). The (potential) impact of Brexit on UK SMEs: regional evidence and public policy implications. Regional Studies, 53(5), 761-770.

Corbett, A., \& Gordon, C. (2018). Brexit higher education and research. Routledge: The Routledge Handbook of the Politics of Brexit.

Dinges, M., Gassler, H., Elixmann, D., Marcus, S., \& Gries, C-I. (2013), SMEs participation under Horizon 2020: Study. Directorate-General for Internal Policies of the Union, European Parliament.

Enger, S. G. (2018). Closed clubs: Network centrality and participation in Horizon 2020. Science and Public Policy, 45(6), 884-896.

European Commission (2017). Interim evaluation of Horizon 2020. Commission staff working document. Luxembourg: Publications Office of the European Union.

Freitag, M., Vatter, A., \& Mueller, S. (2015). Switzerland's Immigration Challenge: Viewpoints and insights in the aftermath of the mass immigration initiative. Swiss Political Science Review, 21(1), 1-4.

Georghiou, L. (2001). Evolving frameworks for European collaboration in research and technology. Research Policy, 30(6), 891-903.

Geske, A., \& Berzina, D. (2017). A two-speed Europe in the area of research. University of Latvia. 
Geuna, A. (1996). The participation of higher education institutions in European Union Framework Programs. Science and Public Policy, 23(5), 287-296.

Geuna, A. (2001). The changing rationale for European university research funding: Are there negative unintended consequences? Journal of Economic Issues, 35(3), 607-632.

Goodwin, M., \& Milazzo, C. (2017). Taking back control? Investigating the role of immigration in the 2016 vote for Brexit. The British Journal of Politics and International Relations, 19(3), 450-464.

Highman, L. (2018). Future EU-UK research and higher education cooperation at risk: What is at stake? Tertiary Education and Management, 25, 45-52.

Lechner, M. (2010). The estimation of causal effects by difference-in-difference methods. Foundations and Trends in Econometrics, 4(3), 165-224.

Leese, M. (2018). Between a carrot and a stick: Science diplomacy and access to EU research funding. Global Policy, 9, 48-52.

Lepori, B., Seeber, M., \& Bonaccorsi, A. (2015a). Competition for talent. Country and organizational-level effects in the internationalization of European higher education institutions. Research Policy, 44(3), 789-802.

Lepori, B., Veglio, V., Heller-Schuh, B., Scherngell, T., \& Barber, M. (2015b). Participations to European Framework Programs of higher education institutions and their association with organizational characteristics. Scientometrics, 105(3), 2149-2178.

Mataković, H., \& Novak, I. R. (2013). Croatia's participation in the Seventh Framework Programme: A moderate success? Business Systems Research, 4(2), 126-143.

Mayhew, K. (2017). UK higher education and Brexit. Oxford Review of Economic Policy, 33, 155-161.

Meyer, B. (1995). Natural and quasi-experiments in economics. Journal of Business \& Economic Statistics, 13(2), 151-161.

Newman, M. E. (2008). The mathematics of networks. The New Palgrave Encyclopedia of Economics, 2(2008), 1-12.

Paier, M., \& Scherngell, T. (2011). Determinants of collaboration in European R\&D networks: empirical evidence from a discrete choice model. Industry and Innovation, 18(1), 89-104.

Robitaille, J. P., Macaluso, B., Pollitt, A., Gunashekar, S., \& Larivière, V. (2015). Comparative scientometric assessment of the results of ERC-funded projects. Prepared for European Commission, Research \& Innovation Directorate-General Unit A1 - Support to the Scientific Council.

Ulnicane, I. (2015). Broadening aims and building support in science, technology and innovation policy: The case of the European Research Area. Journal of Contemporary European Research, 11, 1.

Waltman, L., Calero-Medina, C., Kosten, J., Noyons, E., Tijssen, R. J. W., van Eck, N. J., et al. (2012). The Leiden Ranking 2011/2012: Data collection, indicators, and interpretation. Journal of the American Society for Information Science and Technology, 63(12), 2419-2432. 